\section{Effect of doxycycline on stifle lameness: a preliminary clinical observation in twelve dogs}

\author{
Kei Hayashi, 1 Joseph D. Frank,2 \\ Paul A. Manley, 3 Peter Muir ${ }^{3}$
}

1Department of Surgical \& Radiological Sciences, School of Veterinary Medicine, University of California, Davis; ${ }^{2}$ Fox

Valley Animal Referral Center, Appleton; 3Department of Surgical Sciences, School of Veterinary Medicine, University of Wisconsin, Madison, USA

\section{Abstract}

The clinical efficacy of oral doxycycline was evaluated in twelve dogs with stifle arthritis and a presumptive diagnosis of early cruciate disease. Doxycycline $(2.5-4.5 \mathrm{mg} / \mathrm{kg}$ once daily) was administered orally for 3 to 8 weeks. Eight dogs, who presented prior to the treatment with clinical signs of 4 weeks or fewer duration (group B), had a good response to doxycycline, whereas four dogs with a longer history of lameness (group A) had a poor response. The follow-up periods ranged from 2 to 12 months after discontinuation of the doxycycline treatment (median=6.5 months, 3 months in group A, and 9.5 months in group B). There was a significant correlation between the duration of lameness and the subjective grading of clinical improvement. In $68 \%$ of these cases of dogs with stifle arthritis $(8 / 12)$, the oral administration of doxycycline resulted in the improvement of lameness, even after discontinuation of doxycycline. Careful selection of patients based on the duration of their lameness appears to be crucial in order to achieve a positive outcome.

\section{Introduction}

Stifle arthritis is a common cause of lameness in dogs, which is typically associated with progressive rupture of the cranial cruciate ligament (CCL) during normal activity.1-4 Progression of arthritis and persistent lameness are common even with surgical treatment. ${ }^{1}$ It is generally accepted that CCL rupture occurs because of progressive structural failure in most dogs, and that some underlying pathology predisposes CCL to rupture. ${ }^{2-4}$

Clinical features of this condition and its surgical treatments have been well described. Several risk factors, such as bodyweight, age, and dog phenotype have been identified; however, the CCL rupture mechanism in dogs is poorly understood.2-4 It has been shown that progressive rupture of the CCL is associated with chondroid transformation and necrosis of ligament fibroblasts, and disruption of the normal architecture of type I collagen within the extracellular matrix.3,4 The characteristic changes are associated with a significant reduction in the tensile strength of the CCL. 5 These findings suggest that CCL rupture occurs because of progressive structural failure involving collagen degradation. Type I collagen is a major structural extracellular matrix protein of ligament which provides tissue with its mechanical stiffness and strength. Collagen's unique triple helical molecule is biochemically stable and resistant to many enzymes. Therefore, degradation of collagen requires specific process, which involves specialized proteases. Recent studies indicated that localization of collagenolytic proteases such as cathepsin $\mathrm{K}$ are associated with ruptured CCL. ${ }^{2}$

Based on these findings, we hypothesized that degradation of ligament collagen during progressive rupture is mediated by increased expression of collagenolytic proteases within the tissues of the stifle joint. Therefore, inhibition of collagenolytic enzymes may prevent progressive CCL rupture. Doxycycline is known to inhibit collagenolytic proteases through multiple non-antimicrobial mechanisms, and previous studies have shown that doxycycline inhibits protease activity and nitric oxide production, reducing collagen degradation and progression of arthritis.6,7 Safety of use and efficacy of reducing severity of arthritis by oral administration of doxycycline have been demonstrated in dogs.6,7 The purpose of this study was to evaluate clinical efficacy of oral administration of doxycycline in improvement of clinical signs of dogs with cruciate disease and stifle arthritis.

\section{Materials and Methods}

\section{Criteria for selection of cases}

Twelve dogs were included in this retrospective study (Table 1). In these dogs, presumptive diagnosis of early stifle arthritis was made based on i) presence of clinical signs related to stifle pain; ii) presence of radiographic evidence of stifle effusion; and iii) absence of other identifiable causes of lameness. Dogs were included in this study when the owner declined exploratory stifle arthrotomy/ arthroscopy. Dogs were excluded from this study i) when major stifle instability was detected on palpation by a board certified surgeon under sedation, and ii) when radiographic evidence of moderate to severe arthritic changes were present.
Correspondence: Dr. Kei Hayashi

Department of Surgical \& Radiological Sciences, School of Veterinary Medicine, University of California-Davis, Davis, CA 95616-8745, USA.

E-mail: khayashi@ucdavis.edu

Key words: dog, arthritis, cruciate disease.

Received for publication: 12 March 2011.

Accepted for publication: 9 April 2011.

This work is licensed under a Creative Commons Attribution 3.0 License (by-nc 3.0).

(C) Copyright K. Hayashi et al., 2010

Licensee PAGEPress, Italy

Veterinary Science Development 2011; 1:e7

doi:10.4081/vsd.2011.e7

\section{Protocol}

Doxycycline (2.5-4.5 mg/kg once daily) was orally administered for 3 to 8 weeks (Table 1). 6,7 High impact exercises were limited during treatment. Subjective evaluation of clinical outcome of the treatment was performed by examination of medical record and telephone communication (follow-up range 2 to 12 months after discontinuation of doxycycline, median 6.5 months), using a subjective grading system from 0 to 3 ( $0=$ =worse/no change, 1 =improved, $2=$ greatly improved, $3=$ returned to normal). Dogs were divided into two groups for analytical purpose based on the response to treatment: Group $\mathrm{A}=$ non-responders with subjective grades of 0 and 1 , Group $B=$ responders with subjective grades of 2 or 3. Non-parametric Spearman Rank correlation test was used to analyze correlation between result (subjective grade) and age, body weight, duration of clinical sings prior to the treatment, drug dosage, and duration of treatment (StatView, SAS Institute Inc., Cary, NC, USA). Mann-Whitney U test was used to compare non-parametric date (grades) and student-t test was used to compare the parametric data (age, body weight, and dosage) between groups (StatView). Significant level was set at $\mathrm{P}=0.05$. Data are presented as mean \pm standard deviation.

\section{Results}

Age at the time of presentation was $5.3 \pm 2.7$ (mean \pm standard deviation) years, and body weight was $35.4 \pm 12.3 \mathrm{~kg}$ (Tables 1 and 2). There were no significant differences in age and body weight between groups. The duration of clinical signs of pelvic limb lameness was $12.9 \pm 16.7$ weeks (median $=4$ weeks, range $=2$ 56 weeks). The duration of clinical signs in group A was $32.0 \pm 17.3$ weeks (median $=28$ weeks, range $=16-56$ weeks). The duration of 
Table 1. Summary of cases.

\begin{tabular}{|c|c|c|c|c|c|c|c|c|c|c|}
\hline $\begin{array}{l}\text { Case } \\
\text { no. }\end{array}$ & $\begin{array}{l}\text { Signalment } \\
\text { (sex, breed) }\end{array}$ & $\begin{array}{l}\text { Age } \\
\text { (year) }\end{array}$ & $\begin{array}{l}\text { Body } \\
\text { weight } \\
(\mathrm{kg})\end{array}$ & $\begin{array}{l}\text { Duration of } \\
\text { clinical } \\
\text { signs (week) }\end{array}$ & $\begin{array}{l}\text { Total } \\
\text { (mg) }\end{array}$ & $\begin{array}{c}\text { Doxycycline } \\
\text { dosage } \\
(\mathrm{mg} / \mathrm{kg})\end{array}$ & $\begin{array}{l}\text { Period } \\
\text { (week) }\end{array}$ & $\begin{array}{c}\text { Other } \\
\text { medication }\end{array}$ & $\begin{array}{l}\text { Followup } \\
\text { period } \\
\text { (month)* }\end{array}$ & $\begin{array}{c}\text { Subjective } \\
\text { grade }(0-3)^{\circ}\end{array}$ \\
\hline 1 & NM, Rottwiler & 3 & 33 & 56 & 100 & 3.3 & 8 & & 3 & 0 \\
\hline 2 & NM, St. Bernard Mix & 7 & 39 & 32 & 125 & 3.2 & 4 & Carprofen/CS/G & 2 & 0 \\
\hline 3 & NM, Cairn Terrier & 9 & 10 & 24 & 25 & 2.5 & 8 & Aspirin & 10 & 1 \\
\hline 4 & M, Collie Mix & 8 & 22 & 16 & 100 & 4.5 & 8 & & 3 & 1 \\
\hline 5 & NM, Lab. Retriever & 8 & 47 & 4 & 200 & 4.3 & 8 & $\mathrm{CS} / \mathrm{G}$ & 2 & 2 \\
\hline 6 & SF, Boxer & 4 & 22 & 4 & 100 & 4.5 & 6 & $\begin{array}{l}\text { Deracoxib } \\
\text { (only for the } \\
\text { first } 7 \text { days) }\end{array}$ & 4 & \\
\hline 7 & SF, Lab. Retriever & 3.5 & 40 & 4 & 100 & 2.5 & 8 & & 4 & 2 \\
\hline 8 & SF, Airdale Mix & 6.5 & 36 & 3 & 100 & 2.8 & 8 & & 12 & 2 \\
\hline 9 & SF, German Shepherd & 5 & 40 & 2 & 100 & 2.5 & 8 & & 9 & 2 \\
\hline 10 & SF, Golden Retriever & 7 & 34 & 4 & 100 & 2.9 & 8 & $\mathrm{CS} / \mathrm{G}$ & 10 & 3 \\
\hline 11 & NM, Doberman & 1 & 47 & 3 & 200 & 4.3 & 6 & & 12 & 3 \\
\hline 12 & M, Bull Mastiff & 1.5 & 53 & 2 & 200 & 3.8 & 4 & $\mathrm{CS} / \mathrm{G}$ & 10 & 3 \\
\hline
\end{tabular}

*Period after discontinuation of doxycycline treatment; ${ }^{\circ}$, worse/no change; 1 , improved; 2, greatly improved; 3, returned to normal; M, male; NM, Neutered male; SF, spayed female; CS/G, Chondroitin Sulfate/Glucosamine.

clinical signs in group B was $3.37 \pm 0.74$ weeks (median=3.5 weeks ranged from 2 to 4 weeks). There was a significant difference in duration of lameness between groups $(\mathrm{P}=0.007)$. Doxycycline dosage ranged from $2.5 \mathrm{mg} / \mathrm{kg}$ to $4.5 \mathrm{mg} / \mathrm{kg}$ (Table 1). Treatment period was originally designed to be 6 to 8 weeks, however it was discontinued at 4 weeks in case 2 due to poor response to the treatment, and at 4 weeks in case 12 due to marked improvement. Concurrent use of other medications and oral supplements were noted in the Table 1. Three dogs received chondroitin sulfate-glucosamine, two dogs received non-steroidal anti-inflammatory medication, and one dog received both.

Follow-up period ranged from 2 to 12 months (median=6.5 months, 3 months in group A, 9.5 months in group B) after discontinuation of doxycycline treatment (Table 1). No noticeable side effects were reported. Two dogs underwent surgical treatment due to lack of response and progression of lameness (cases 1 and 2), and two dogs showed no signs of improvement (cases 3 and 4). It is not known whether these dogs developed stifle instability during doxycycline treatment. The remaining 8 dogs in group B $(8 / 12=67 \%)$ showed improvement of clinical signs. Owners reported marked improvement in resolution of lameness in cases 5 to 9 , with occasional mild lameness only after exercise. In cases 10 to 12 , the owners did not notice any lameness and felt that dogs returned to normal. There was a significant negative correlation between duration of clinical sign and subjective grading of clinical improvement (shorter duration of lameness, better result) $(\mathrm{P}=0.029)$ (Figure 1). There was a significant positive correlation between body weight and subjective grading of clinical improvement $(\mathrm{P}=0.044)$.

Table 2. Comparison between two groups.

\begin{tabular}{lcc} 
& $\begin{array}{c}\text { Group } \mathbf{A}-\text { Non-responders } \\
\text { Grade } 0 \text { or } \mathbf{1}(\mathbf{n}=4)\end{array}$ & $\begin{array}{c}\text { Group B - Responders } \\
\text { Grades } 2 \text { or } 3(\mathbf{n}=8)\end{array}$ \\
Age (years) & $6.75 \pm 2.63$ & $4.56 \pm 2.54$ \\
Body weight $(\mathrm{kg})$ & $26.0 \pm 12.8$ & $40.0 \pm 9.54$ \\
\hline Duration of lameness (weeks) & $32.0 \pm 17.3$ & $3.37 \pm 0.74$ \\
& range $=16-56$, median $=28^{*}$ & range $=2-4$, median $=3.5^{*}$ \\
Dosage $(\mathrm{mg} / \mathrm{kg})$ & $3.32 \pm 0.87$ & $3.43 \pm 0.85$
\end{tabular}

*P=0.007 with non-parametric Mann-Whitney U test.

\section{Discussion}

The mixed result of this retrospective study suggested that oral administration of doxycycline may be an effective and practical therapeutic option for dogs with stifle arthritis and a short duration of lameness of less than 4 weeks, although the effect of other medication and oral supplement or forced rest may have affected the observed outcome. The observed efficacy appears to be continuous even after discontinuation of doxycycline treatment at this short term follow-up ( 2 to 12 months, median $=9.5$ months). This study suggests that oral doxycycline administration, a potential treatment option for cruciate disease and inflammatory stifle arthritis in dogs, warrants further investigation.

The mechanism of degenerative CCL rupture in the dog is poorly understood. Previous studies have proposed involvement of genetic factors, conformational abnormalities, agerelated degenerative changes, and immunemediated inflammatory joint disease in its pathogenesis. Rupture of the CCL has been associated with inflammation of the synovial lining of stifle, the synovial fluid, and the epiligament of the CCL, where release of col-

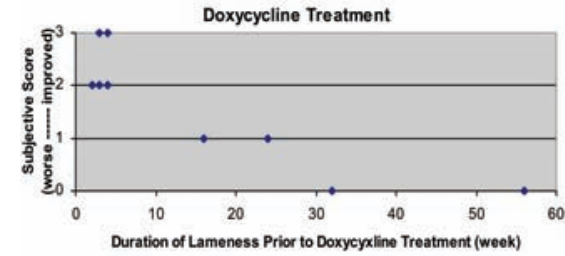

Figure 1. Subjective score of lameness after doxycycline treatment $(0=$ worse/no change, $1=$ improved, $2=$ greatly improved, 3 =returned to normal), plotted against duration of lameness before initiation of doxycycline treatment (week). Note clinical improvement of lameness in dogs with short duration of lameness (less than 4 weeks) at the time of presentation, prior to the treatment.

lagenolytic proteases from the synovium into stifle synovial fluid can be elevated and degrade the structural integrity of the CCL. 8,9 Recent studies demonstrated that localization of collagenolytic proteases in synovium and CCL epiligament is associated with CCL rupture.2,3 Therefore, collagenolytic enzymes can be theoretical target for a treatment to control collagen degradation in canine stifle arthritis. Doxycycline is known to inhibit collagenolytic 
proteases through multiple non-antimicrobial mechanisms. Prophylactic treatment of oral doxycycline has been reported to reduce severity of experimentally-induced osteoarthritis in dogs. ${ }^{6}$ Inhibition of nitric oxide production, but not stromelysin, by doxycycline has been reported in canine cruciate disease. ${ }^{7}$ Doxycycline has also been used clinically to treat chronic periodontal disease in human, a condition characterized by excessive collagen degradation. ${ }^{10}$ Mechanisms of action in these reports are thought to be due to doxycycline's anti-enzymatic or anti-inflammatory actions. Interestingly, a recent study by Muir et al demonstrated the presence of bacterial DNA in the stifle with naturally occurring canine cruciate disease, suggesting involvement of infectious component in pathogenesis of the canine cruciate disease.11 Therefore, it is possible that anti-microbial action of doxycycline, in addition to its anti-enzymatic or anti-inflammatory action, is a potential explanation for clinical efficacy in dogs with stifle arthritis.

\section{Conclusion}

In this clinical trial, oral administration of doxyxycline in dogs with stifle arthritis resulted in inconsistent efficacy, where subjective improvement of lameness was observed in $68 \%$ (8/12) of cases. Limitations of this study include a small case population, lack of control groups, lack of definitive diagnosis of CCL rup- ture, and lack of statistical analysis of objective data. Therefore, further prospective controlled studies need to be conducted. Careful selection of patients based on duration of lameness appears crucial for positive outcome. To develop novel disease-modifying therapeutic strategies for canine stifle arthritis, identification of key factors in its pathogenesis such as causative microorganisms or proteases, and development of methods to detect early cruciate disease such as specific biomarkers are needed.

\section{References}

1. Innes JF, Bacon D, Lynch C, Pollard A. Long-term outcome of surgery for dogs with cranial cruciate ligament deficiency. Vet Rec 2000;147:325-8.

2. Muir P, Hayashi K, Manley PA, et al. Evaluation of tartrate-resistant acid phosphatase and cathepsin $\mathrm{K}$ in ruptured cranial cruciate ligament in dogs. Am J Vet Res 2002;63: 1279-84.

3. Hayashi K, Frank JD, Hao Z, et al. Histological changes in the canine cranial cruciate ligament after rupture. Vet Surg 2003;32:269-77.

4. Hayashi K, Frank JD, Hao Z, et al. Evaluation of ligament fibroblast viability in ruptured cranial cruciate ligament of dogs. Am J Vet Res 2003;64:1010-16.

5. Vasseur PB, Pool RR, Arnoczky SP, Lau RE. Correlative biomechanical and histologic study of the cranial cruciate ligament in dogs. Am J Vet Res 1985;46:1842-54.

6. Yu LP Jr, Smith GN Jr, Brandt KD, et al. Reduction of the severity of canine osteoarthritis by prophylactic treatment with oral doxycycline. Arthr Rheum 1992;35:1150-9.

7. Jauernig S, Schweighauser A, Reist M, et al. The effects of doxycycline on nitric oxide and stromelysin production in dogs with cranial cruciate ligament rupture. Vet Surg 2001;30:132-9.

8. Galloway RH, Lester SJ. Histopathological evaluation of canine stifle joint synovial membrane collected at the time of repair of cranial cruciate ligament rupture. J Am Anim Hosp Assoc 1995;31:289-94.

9. Goldberg VM, Burstein A, Dawson M. The influence of an experimental immune synovitis on the failure mode and strength of the rabbit anterior cruciate ligament. J Bone Joint Surg Am 1982;64:900-6.

10. Suzuki A, Yagisawa J, Kumakura S, Tsutsui T. Effects of minocycline and doxycycline on cell survival and gene expression in human gingival and periodontal ligament cells. J Periodontal Res 2006;41: 124-31.

11. Muir P, Oldenhoff WE, Hudson AP, et al. Detection of DNA from a range of bacterial species in the knee joints of dogs with inflammatory knee arthritis and associated degenerative anterior cruciate ligament rupture. Microb Pathog 2007;42:4755 . 